\title{
Radiation Proctitis and Management Strategies
}

\author{
Dushyant Singh Dahiya', Asim Kichloo ${ }^{1,2}$, Faiz Tuma ${ }^{3}$, Michael Albosta', and Farah Wani ${ }^{4}$ \\ ${ }^{1}$ Department of Internal Medicine, Central Michigan University, Saginaw, MI, ${ }^{2}$ Department of Internal Medicine, Samaritan Medical \\ Center, Watertown, NY, ${ }^{3}$ Department of Surgery, Central Michigan University, Saginaw, MI, ${ }^{4}$ Department of Family Medicine, Samaritan \\ Medical Center, Watertown, NY, USA
}

Radiotherapy (RT) is a treatment modality that uses high-energy rays or radioactive agents to generate ionizing radiation against rapidly dividing cells. The main objective of using radiation in cancer therapy is to impair or halt the division of the tumor cells. Over the past few decades, advancements in technology, the introduction of newer methods of RT, and a better understanding of the pathophysiology of cancers have enabled physicians to deliver doses of radiation that match the exact dimensions of the tumor for greater efficacy, with minimal exposure of the surrounding tissues. However, RT has numerous complications, the most common being radiation proctitis (RP). It is characterized by damage to the rectal epithelium by secondary ionizing radiation. Based on the onset of signs and symptoms, post-radiotherapy RP can be classified as acute or chronic, each with varying levels of severity and complication rates. The treatment options available for RP are limited, with most of the data on treatment available from case reports or small studies. Here, we describe the types of RT used in modern-day medicine and radiation-mediated tissue injury. We have primarily focused on the classification, epidemiology, pathogenesis, clinical features, treatment strategies, complications, and prognosis of RP. Clin Endosc 2022;55:22-32

Key Words: Colorectal Neoplasms; Proctitis; Radiation; Rectum

\section{INTRODUCTION}

Radiation therapy (RT) is a treatment modality based on the utilization of high-energy rays or radioactive agents to generate ionizing radiation against rapidly dividing cells. The main objective of RT for the treatment of cancer is to impair or halt tumor cell division. ${ }^{1}$ The discovery of X-rays in 1895 by Wilhelm Conrad Röntgen sparked great interest within the scientific community to study the physiological effects of radiation and utilize it in the treatment of cancers. ${ }^{2-4}$ Over the past few decades, with advancement in technology, the introduction of newer methods of RT, and a better understanding

Received: November 3, 2020 Revised: January 4, 2021

Accepted: January 30, 2021

Correspondence: Michael Albosta

Department of Internal Medicine, Central Michigan University, 1000 Houghton Ave, Saginaw, MI 48602, USA

Tel: +1-989-295-2176, Fax: +989-774-7547, E-mail: albos1ms@cmich.edu ORCID: https://orcid.org/0000-0003-4187-4911

(c) This is an Open Access article distributed under the terms of the Creative Commons Attribution Non-Commercial License (http://creativecommons.org/ licenses/by-nc/3.0) which permits unrestricted non-commercial use, distribution, and reproduction in any medium, provided the original work is properly cited. of the pathophysiology of cancers has enabled physicians to deliver doses of radiation that match the exact dimensions of the tumor for greater efficacy, with minimal exposure of surrounding tissues. However, radiation proctitis (RP) is one of the most common complications of radiation to the pelvis. It is characterized by damage to the rectal epithelium by secondary ionizing radiation therapy. Based on the time from initiation of $\mathrm{RT}$ to the development of the presenting signs and symptoms, RP can be classified into two subtypes, acute and chronic. Acute RP is usually self-limiting with minimal complications; however, chronic RP tends to be more severe and is often associated with numerous complications. The diagnosis can be established via direct visualization through rigid or flexible sigmoidoscopy and microscopic evaluation; however, the procedure should always be performed by a highly experienced gastroenterologist or colorectal surgeon because the friable mucosa is highly prone to perforation. The treatment options available for RP are limited, with most of the data on treatment strategies available from case reports or small studies. In this review of the literature, we describe the types of RT and their utilization in modern-day medicine. We have also discussed the classification, epidemiology, pathogenesis, clinical mani- 
festations, tools to establish the diagnosis, treatment strategies, complications, and prognosis of RP. Furthermore, we highlight the need for additional large, multicenter prospective studies to determine the burden of RP, to better understand the pathogenic mechanisms, identify additional risk factors that increase the incidence of RP, and compare different treatment modalities.

\section{HISTORY OF RADIOTHERAPY}

$\mathrm{RT}$ is a treatment modality based on the utilization of high-energy rays or radioactive agents, with the intent to impair or halt the division of tumor cells. ${ }^{1}$ Before the advent of ionizing radiation, there were limited therapeutic options available for the management of cancers; however, the discovery of X-rays in 1895 by Wilhelm Conrad Röntgen revolutionized the treatment of cancers. ${ }^{2}$ After a year of its discovery, and before its physiological effect on tissues were completely understood, X-rays were already being used in treating a patient with breast cancer by Emil Herman Grubbe. ${ }^{3}$ Within the scientific community, the discovery of ionizing radiation sparked an immense interest towards studying the phenomenon of radioactivity, and determining its physiological effects on tissues and organ systems while also exploring other potential natural sources of radiation. Over the last century, RT alone, or combined with other treatment modalities, has served an essential role in managing numerous cancers. ${ }^{5}$

\section{EXTENT OF UTILIZATION OF RADIOTHERAPY}

From a treatment perspective, literature reports that RT is an important curative treatment modality for locoregional tumors, and is used in at least two-thirds of cancer treatment regimens, particularly in western countries. ${ }^{6}$ It is important to glance at the statistics regarding patients with cancer to understand the extent of utilization of RT in clinical practice. As of January 2019, more than 16.9 million Americans (8.1 million males and 8.8 million females) were alive with a history of cancer. ${ }^{7.8}$ This number has been projected to increase to 22.1 million by January $2030 .^{8}$ Furthermore, the percentage of cancer survivors who will receive RT has been projected to increase from $24 \%$ in 2000 to $29 \%$ by the end of 2020 , and it is further estimated to decline slightly to $28 \%$ by 2030 . $^{9}$ This makes up a sizable population of patients who have received or will receive RT. Additionally, over the past few decades, with substantial technological advancement, the introduction of newer meth- ods for RT, and a better understanding of the pathophysiology of cancers on a molecular level, has enabled physicians to deliver doses of radiation that match the exact dimensions of the tumor. ${ }^{10}$ This prevents excessive and unnecessary radiation exposure to normal tissues, thereby limiting tissue injury and increasing the efficacy of $\mathrm{RT}^{10}$

\section{TYPES OF RADIOTHERAPY}

$\mathrm{RT}$ to the pelvis is an important component of the treatment regimens available for pelvic cancers. It can be administered as adjuvant or neoadjuvant RT. Higher doses of radiation may be required for treating rectal cancers as they usually show resistance to low-dose $\mathrm{RT}^{11}$ The modes through which RT can be delivered include external beam radiation and brachytherapy. ${ }^{11-16}$

\section{External beam radiation}

It is administered via an external photon generator, with various sources, including gamma rays, electron beams, and $\mathrm{X}$-rays, with a four-beam approach. External beam radiation usually results in significant exposure to the surrounding tissues. However, newer methods of external beam radiation, such as three-dimensional conformal radiation therapy and intensity-modulated radiation therapy, allow for the utilization of higher doses of radiation to targeted tissues with significantly less exposure to normal tissues. This leads to significantly less radiation damage to normal tissues.

\section{Brachytherapy}

It consists of two methods of delivering radiation in a highly site-specific manner, intending to minimize damage to the surrounding tissues. The most common method is implanting radioactive pellets, usually iodine 125 or palladium 103 , into targeted tissues, with a gradual release over time. An alternative method involves the use of hollow catheters progressively filled with increasing amounts of radioactive pellets over time. Compared with external beam radiation, brachytherapy has shown decreased rates of both acute (6\% vs. $43 \%$ ) and chronic ( $2 \%$ vs. $21 \%$ ) complications.

However, as with any treatment modality, there are side effects and complications. With the use of higher doses of radiation for the treatment of cancers, RP is one of the most common complications. ${ }^{17}$ Physicians are beginning to encounter more cases of RP due to the increasing number of cancer survivors and the fact that most of these patients have undergone RT as a part of their treatment regimens. 


\section{RADIATION PROCTITIS AND ITS CLASSIFICATION}

$\mathrm{RP}$ is often a misleading term because it implies a continuous chronic inflammatory process in the rectum; however, it continues to be widely used in the literature. Radiation proctopathy is the correct terminology for radiation-induced damage to the rectum. It is characterized by damage to the rectal epithelium secondary to ionizing radiation therapy. The degree of RP is variable and is dependent on both radiation and patient-associated risk factors. ${ }^{18}$ Based on the time from initiation of RT to the development of the presenting signs and symptoms, it can be classified into two main subtypes.

\section{Acute radiation proctitis}

It is characterized by the involvement of only the superficial mucosa of the rectum. ${ }^{19}$ It is a highly dose-dependent phenomenon and can occur almost immediately or within 3 months of initiation of RT. ${ }^{20}$

\section{Chronic radiation proctitis}

It is a more complex clinical entity characterized by the involvement of the full thickness of the rectal mucosa along with fibrosis and obliterative arteritis. ${ }^{21}$ It usually has a delayed onset. ${ }^{22,23}$ The first symptoms may often be seen at 9-14 months following radiation exposure but can occur at any time post-radiation for up to 30 years. 22,23

\section{EPIDEMIOLOGY OF RADIATION PROCTITIS}

Due to variability and lack of consensus among physicians in the definition and reporting of RP, it has been challenging to establish the exact incidence rate. In literature, the incidence rate of chronic RP is estimated to range from $2 \%-20 \%{ }^{21}$ The incidence of RP in patients treated with brachytherapy alone is estimated to range from $8 \%-3 \%$ vs. $21 \%$ when used in combination with other therapies. ${ }^{24}$ Literature also reports a variable prevalence of chronic RP, ranging from as low as $5 \%-20 \%$ to as high as $47 \%$ in patients treated with RT for cervical cancers. ${ }^{25,26}$ Furthermore, a retrospective study by Willet revealed that patients with inflammatory bowel disease (IBD) are at increased risk of developing RP along with other complications from external beam radiation, and the reported incidence rate of the complications was found to be $46 \%$ at 32 months. ${ }^{27}$ Additionally, malignancies associated with human immunodeficiency virus (HIV)/acquired immunodeficiency syndrome (AIDS), such as cervical cancer, anal cancer, and lymphomas, are on the rise and may require RT directed towards the rectum. ${ }^{11}$ No comprehensive data currently exists on the incidence and prevalence of RP in these patients; however, studies have reported increased toxicity and decreased tolerance to radiation in patients with HIV/AIDS and low CD4 counts. ${ }^{28,29}$ Hence, we strongly advocate for additional large prospective, multicenter studies to investigate the exact epidemiology of RP and also to determine the radiation dose adjustments required in proinflammatory and immunocompromised states.

\section{RISK FACTORS FOR RADIATION-MEDIATED TISSUE INJURY}

Several risk factors have been identified and associated with gastrointestinal (GI) injury secondary to RT. They can be subdivided into patient-associated or radiation-associated risk factors.

\section{Radiation-associated risk factors}

GI injury secondary to RT is highly contingent on the modality through which radiation is delivered, the dose of radiation, the total duration of radiation, the area of exposure, and the intensity of radiation. ${ }^{18,30}$ A radiation dose of $<45$ Gy is associated with minimal long-term effects, whereas more complications have been reported in patients receiving doses between $45 \mathrm{~Gy}$ and $70 \mathrm{~Gy}$, although these are of lesser intensity compared with higher doses of radiation. ${ }^{31,32}$ Patients receiving doses > 70 Gy sustain longstanding injury to surrounding tissues. $^{31,32}$ The mode of delivery of radiation also plays a considerable role, and literature reports fewer complications in patients receiving brachytherapy as compared to external beam radiation. ${ }^{11}$ Additionally, combinations of chemotherapy with RT have also been shown to increase the risk of intestinal toxicity. ${ }^{33,34}$

\section{Patient-associated risk factors}

Certain patient-specific characteristics have also been linked to an increased risk of intestinal radiation injury. Conditions like hypertension, diabetes mellitus, atherosclerosis, and smoking are presumed to increase intestinal ischemia and vascular injury post radiation and may also hinder tissue repair. ${ }^{11}$ Furthermore, patients aged $<60$ years have also been reported to have an increased risk of radiation injury. ${ }^{35}$ However, it is unclear whether these patients demonstrate an increased radiation-induced inflammatory response or if they are more likely to notice and report clinical symptoms compared with an older demographic. ${ }^{35}$ As discussed earlier, patients with IBD have a greater risk of radiation-induced damage to the GI tract. ${ }^{27}$ Literature also reports that patients with collagen vascular diseases such as scleroderma, systemic lupus erythema- 
tosus, rheumatoid arthritis, and polymyositis are more prone to radiation-induced injury to the GI tract because of their low radiation tolerance. ${ }^{36,37}$

\section{PATHOGENESIS OF RADIATION PROCTITIS}

The pathogenesis of RP is complex and yet to be fully understood. To better comprehend the pathogenic process, it is divided into two sections.

\section{Mechanism of radiation-mediated tissue damage}

It is essential to first understand the mechanism by which ionizing radiation causes damage to tissues at the cellular level. The damage to tissues secondary to RT is widespread; however, in essence, both direct and indirect mechanisms of tissue damage via radiation target cellular deoxyribonucleic acid (DNA), thereby inhibiting transcription and preventing cellular replication. ${ }^{38}$ Through the direct mechanism, ionizing radiation directly damages the DNA or cell membrane. It can induce double-stranded DNA breaks, cause inter- and intra-strand cross-linkages, or mutations of the DNA and can compromise the rigidity of the phospholipid bilayer and the electrical gradient of the cell membrane. ${ }^{39}$ The indirect mechanism involves the generation of free radicals from the ionization of water molecules, leading to oxidative stress injuries. ${ }^{40}$ However, as this radiation-induced damage is in process, DNA repair mechanisms are activated to fix the DNA strands. At low doses of radiation, the repair mechanisms are successful and lead to the resolution of DNA injuries. ${ }^{41}$ However, at higher doses, the ionizing radiation can overwhelm the DNA repair mechanism, leading to apoptosis of the cell or inhibition of mitosis. ${ }^{39}$ It is also important to note that cells with high rates of mitosis, such as stem cells and cancers, are most affected by RT.

\section{Tissue response to radiation and pathogenesis of radiation proctitis}

The mucosa of the GI tract is highly proliferative. As per the literature, enterocytes have the highest turnover rate of any fixed cell in the body. ${ }^{42}$ Hence, the rapidly dividing mucosal stem cells present within the crypts of Lieberkühn are highly susceptible to radiation injury. Initiation of RP occurs via radiation-induced damage to the mucosa, followed by late indolent connective tissue growth and remodeling, and subsequently tissue response to the ongoing ischemia. ${ }^{43}$ Damage to the rapidly dividing intestinal crypt stem cells in the radiation field leads to their depletion, resulting in crypt involution, mucosal injury, and exposure of the underlying lamina propria to luminal bacteria. ${ }^{20}$ An acute inflammatory response may be generated after exposure to the bacteria, often involving T-lymphocytes, macrophages, and neutrophils. ${ }^{20}$ Additional damage to the extracellular matrix, mucosa, and submucosa of the bowel wall may be secondary to the production of enzymes and reactive oxygen species. ${ }^{44,45}$ On gross visualization, early radiation injury will show edema, mucosal hyperemia, and ulceration of the tissue. Histological changes of early radiation damage may be seen within a few hours of RT, followed by infiltration of leukocytes and crypt abscess formation in 2-4 weeks. ${ }^{39}$ Subsequently, progressive occlusive vasculitis with foam cell invasion of the intima and hyaline thickening of the media of arterioles may be seen, which contributes to obliterative endarteritis, leading to full-thickness ischemia of the bowel wall. ${ }^{20,46} \mathrm{After}$ cessation of RT, the acute inflammatory process subsides, and intestinal crypt cells start to regenerate. Animal models suggest that migration and engraftment of stem cells from the bone marrow may be responsible for the repair of damaged crypts. ${ }^{47,48}$ However, in some patients, for reasons unknown, the inflammatory process may exaggerate, leading to ulceration of the mucosa followed by fibrosis and the development of chronic inflammatory changes. ${ }^{20}$ Additionally, radiation can directly damage the vascular and endothelial cells leading to full-thickness bowel ischemia; hence, it plays a major role in the pathogenesis of $\mathrm{RP}^{49,50}$

\section{CLINICAL MANIFESTATIONS OF RADIATION PROCTITIS}

The clinical presentation varies for both acute and chronic RP. Not only does the time of the onset of symptoms from the initiation of RT vary between the two, but patients with chronic RP have more severe symptoms. Patients with acute RP may present with diarrhea, nausea, cramps, tenesmus, urgency, mucus discharge, and minor bleeding in approximately $20 \%$ of the cases, which may interrupt treatment. ${ }^{51}$ Patients with chronic RP may have all the symptoms of acute RP and additional symptoms secondary to full-thickness bowel ischemia and fibrotic changes, such as features of malabsorption, severe bleeding, the formation of strictures, perforations, fistulas, and bowel obstruction. ${ }^{52}$ Involvement of the anal sphincter may lead to fecal incontinence. ${ }^{18}$ Conditions that affect microvascular circulation, such as diabetes and peripheral arterial disease, also increase the risk of chronic RP. ${ }^{31,32}$ For patients who present with symptoms of chronic RP several years after $\mathrm{RT}$, it is essential to rule out recurrence of malignancy. Other conditions sharing common symptoms with chronic RP, such as parasitic infections, Clostridium difficile infection, sexually transmitted diseases associated with proctitis such as gonor- 
rhea, herpes simplex virus infection, cytomegalovirus infection, medication-induced colitis, and chronic bowel ischemia, should also be ruled out. Results of physical examination of patients with RP may be unremarkable. However, in some patients, a digital examination may reveal anorectal stenosis, while in others, the examination may be extremely painful due to extensive involvement of the GI tract. ${ }^{18}$ To better understand and assess the extent of rectal toxicity associated with RT, numerous grading criteria have been developed. A commonly used classification system is the Radiation Therapy Oncology Group (RTOG) and the European Organization for Research and Treatment of Cancer (EORTC) scoring system. ${ }^{53}$ The RTOG scoring system describes acute toxicity, whereas the EORTC scoring system classifies chronic toxicity. However, in patients with chronic toxicity, their accuracy and validity have been challenged. ${ }^{54}$ Furthermore, the National Cancer Institute of the National Institutes of Health have published standardized definitions for adverse events, known as the Common Terminology Criteria for Adverse Events (CTCAE) grading system to describe the severity of toxicity in patients receiving cancer therapy. ${ }^{55}$ For patients with proctitis, the CTCAE grading system is summarized in Table $1 .^{55}$

Table 1. Common Terminology Criteria for Adverse Events Grading System for Proctitis According to the National Cancer Institute of the National Institutes of Health

\begin{tabular}{ll}
\hline Proctitis & Rectal discomfort. \\
Grade 1 & $\begin{array}{l}\text { So intervention indicated. } \\
\text { Medical intervention indicated. }\end{array}$ \\
Grade 2 & $\begin{array}{l}\text { Severe symptoms, fecal urgency or stool incontinence; limiting self-care activity of daily living. } \\
\text { Medical intervention or hospitalization indicated. }\end{array}$ \\
Grade 3 & $\begin{array}{l}\text { Life-threatening consequences. } \\
\text { Grade } 4\end{array}$ \\
Grade 5 & Death.
\end{tabular}

\section{DIAGNOSING RADIATION PROCTITIS}

The diagnosis of RP can be established via direct visualization through rigid or flexible sigmoidoscopy. The procedure should always be performed by an experienced gastroenterologist or colorectal surgeon, because the friable mucosa is highly prone to perforation. In patients with acute RP, gross visualization of the rectal mucosa may reveal it to be beefy red, edematous, with ulceration or sloughing (Fig. 1). ${ }^{11,56,57} \mathrm{~A}$ microscopic evaluation may reveal distortion of the microvilli, hyperemia, edema, and ulceration. ${ }^{11,56}$ A colonoscopic biopsy is not recommended in acute RP due to the increased risk of bleeding and fistula formation. ${ }^{11}$ In cases of chronic RP, grossly, the mucosa may appear pale, noncompliant with telangiectasias, and may also have strictures, ulcerations, fistulas, or heavy bleeding (Fig. 2). ${ }^{21,58}$ Microscopically, there may be intimal fibrosis with focal destruction or distortion of the small arteries or arterioles. ${ }^{21}$ In few patients with chronic RP, multiple areas of strictures may be noted, making it challenging to

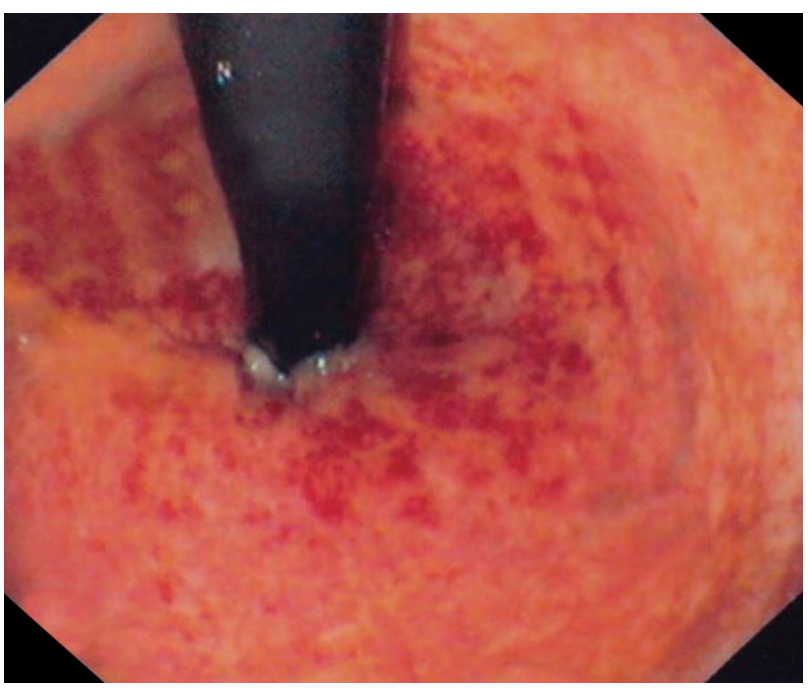

Fig. 1. Endoscopic findings of acute radiation proctitis. Rectal mucosa shows erythema, petechiae and bleeding. Adapted from the article of Katsanos $\mathrm{KH}$ et al. Ann Gastroenterol 2012;25:65, with permission. 


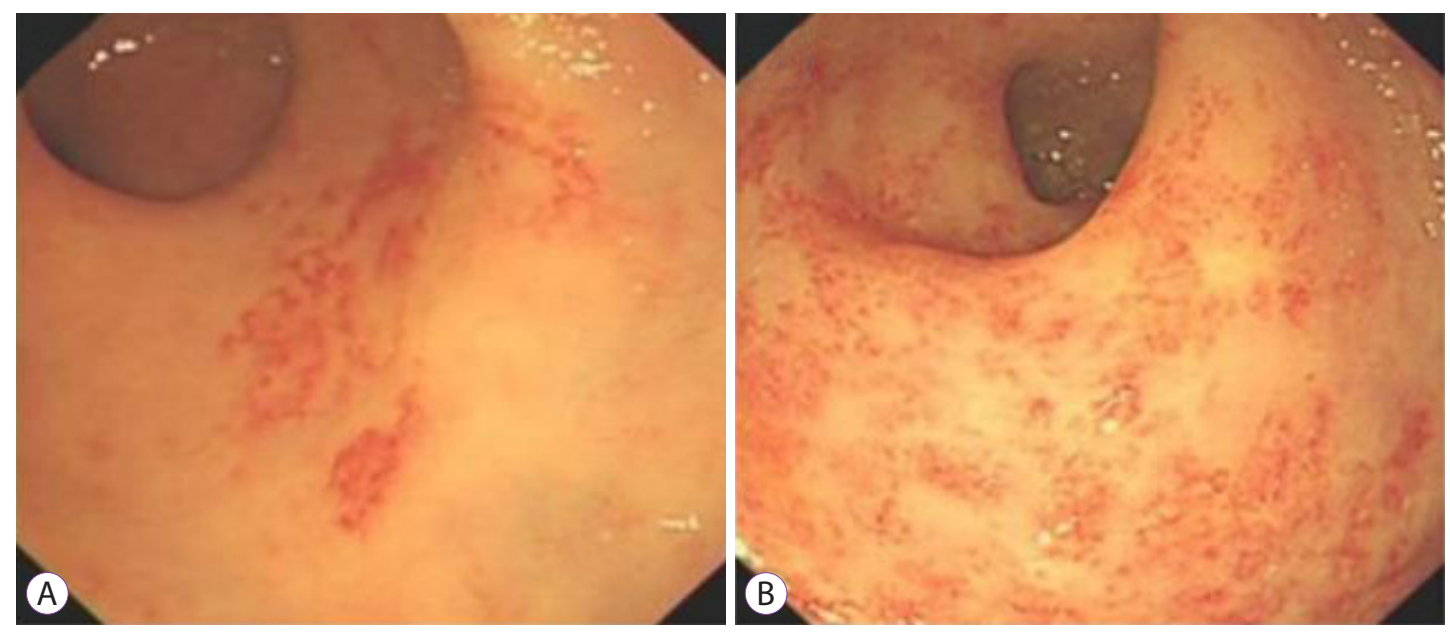

Fig. 2. Endoscopic finding of chronic radiation proctitis. Rectal mucosa shows telangiectasias. Adapted from the article of Zhong Q-H et al. World J Gastroenterol 2019;25:1618-1627, with permission.

distinguish it from a malignancy. ${ }^{59}$ A computed tomography scan can be used to rule out recurrent malignancy, and magnetic resonance imaging should be performed in patients with suspected fistulas. Barium or water-soluble enema studies may also be performed, which can reveal strictures, obstruction, shortening, and narrowing of the rectosigmoid area with loss of normal curvature. ${ }^{18}$

\section{TREATMENT STRATEGIES FOR RADIATION PROCTITIS}

Unfortunately, there are no large, multicenter, randomized clinical trials evaluating the treatment options for RP; hence, most of the data on treatment have been obtained from case reports and small clinical trials. ${ }^{60,61}$ The treatment algorithm for RP is summarized in Fig. 3 . $^{62}$

Acute RP is often self-limiting and does not increase the risk of developing chronic RP. Approximately $20 \%$ of patients undergoing external beam radiation may require a short interruption of therapy. Treatment of patients with acute RP is usually supportive, consisting of hydration, anti-diarrheal agents, and butyrate enemas to promote tissue healing. ${ }^{63}$

The American Society of Colon and Rectal Surgeons (ASCRS) has proposed clinical practice guidelines for treating chronic RP. The treatment options available for chronic RP are discussed in the following sections. ${ }^{62}$

\section{Medical management}

Formalin (formaldehyde 4\%-10\%) has been used in treating chronic RP over the past few decades. ${ }^{64} \mathrm{~A}$ formalin-soaked gauze can be applied directly to the mucosa via rigid proctoscopy under light sedation, and it brings about chemical cauterization of the ulcers and telangiectasias, thereby achieving hemostasis. ${ }^{65}$ Literature reports that after the first application of formalin, the symptoms were resolved in $50 \%$ of the patients, and most patients required an average of only two treatment sessions. ${ }^{62}$ Sucralfate retention enemas have been found to be moderately effective and may also be used for rectal bleeding from chronic RP. ${ }^{62}$ According to the latest guidelines by ASCRS, short-chain fatty acid enemas are not useful; hence they are not recommended for chronic $\mathrm{RP}^{62,66}$ Similarly, other treatment modalities, such as ozone therapy, mesalamine, and metronidazole, have not proven to be efficacious and therefore are not recommended by ASCRS. The medical management for chronic RP is summarized in Table $2 .^{62}$

\section{Endoscopic management}

ASCRS recommends using argon beam plasma coagulation (APC) as it is a safe and effective modality for treating chronic $\mathrm{RP}^{62}$ APC uses an ionized gas, argon, to transmit high-frequency energy to tissues. The literature reports the need for a median of two APC sessions (range: 1-5 sessions) to control rectal hemorrhage, thereby resulting in cessation or a substantial decrease in bleeding in $79 \%-100 \%$ of the patients. ${ }^{62,67}$ Patients who develop rectal ulceration post-APC therapy can be treated with mesalamine suppositories and/or glucocorticoid enemas. ${ }^{68}$ A complete bowel lavage should be performed prior to APC therapy to evacuate combustible gas and prevent bowel explosion with perforation. ${ }^{69}$ Neodymium-doped yttrium aluminum garnet laser can also be used to coagulate the bleeding vessel in these patients. ${ }^{70}$ It has shown symptomatic 


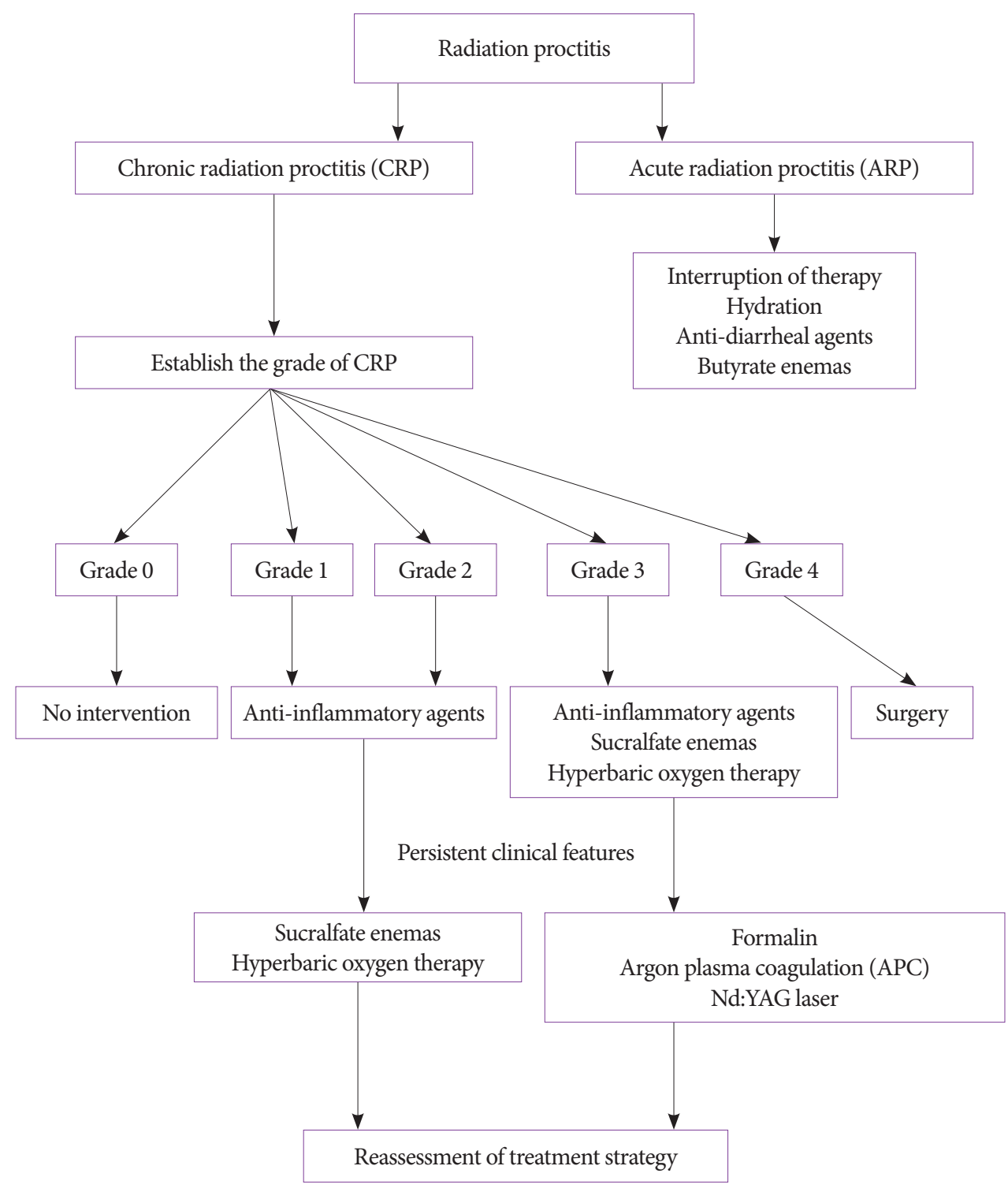

Fig. 3. Treatment algorithm for radiation proctitis in accordance with the American Society of Colon and Rectal Surgeons.

Table 2. Medical Management for Chronic Radiation Proctitis in Accordance with the American Society of Colon and Rectal Surgeons

\begin{tabular}{ccc}
\hline Medical Management & Mechanism & Recommendation \\
\hline Formaldehyde (formalin) & Chemical cauterization & Strong recommendation based on moderate-quality evidence (1B). \\
Sucralfate retention enema & Prevents arterial injury & Strong recommendation based on low-quality evidence (1C). \\
\hline Short chain fatty acid enema & Anti-inflammatory & Weak recommendation based on moderate-quality evidence (1B). \\
Mesalamine & Anti-inflammatory & Not adequately evaluated. Not recommended. \\
Metronidazole & Anti-inflammatory & Not adequately evaluated. Not recommended. \\
Ozone therapy & Anti-inflammatory & Not adequately evaluated. Not recommended. \\
\hline
\end{tabular}


improvement in $78 \%$ of the patients; however, it is expensive and not widely available. ${ }^{70}$ The American Society for Gastrointestinal Endoscopy has also proposed guidelines for using endoscopic therapy, such as electrocoagulation, heater probe, radiofrequency ablation, and cryoablation, for chronic $\mathrm{RP} .^{71}$ However, additional studies are still needed to determine their safety and efficacy. Therefore, they may be used on a case-bycase basis and have received a Grade $1 \mathrm{C}$ recommendation for use by the ASCRS. ${ }^{62}$

\section{Hyperbaric oxygen therapy}

It has emerged as an effective treatment modality for non-healing wounds secondary to chronic RP. The theorized mechanism of action of hyperbaric oxygen therapy (HBOT) is based on improved tissue oxygenation, possible angiogenesis, and antibacterial effects. ${ }^{62}$ Multiple large studies have proven the substantial benefit of HBOT in patients with chronic $\mathrm{RP}^{72,73}$ However, it is expensive, and requires specialized equipment and personnel, and several weeks of therapy; hence, it is not widely available.

\section{Surgical intervention}

Surgery is reserved for patients who fail to show improvement in their symptoms following medical or endoscopic management or in patients with severe complications of RP, such as strictures leading to bowel obstruction, perforations, or fistulas. ${ }^{62}$ As per the literature, approximately $10 \%$ of the patients with RP may require surgical intervention. ${ }^{74}$ In severe cases, proctectomy may become necessary; however, there is no universally approved first-line approach for the surgery. ${ }^{75}$ Resection of the rectum remains highly controversial as it is challenging to perform a safe anastomosis in the radiation-injured tissue and carries a high risk of anastomotic leakage and mortality from postoperative peritonitis. ${ }^{76}$ Diversion of the bowel segment in the form of ileostomy or colostomy has demonstrated significant improvement in the quality of life without further surgical interventions. ${ }^{77}$ It reduces bacterial contamination and irritation injury to the irradiated tissues by the fecal stream. ${ }^{78}$ This decreases rectal bleeding and promotes healing of the tissue. ${ }^{78}$ It may also accelerate the course of fibrosis of the bowel mucosa, thereby preventing the conversion of deep ulcerations into fistulas. ${ }^{78}$ Although ostomy may improve the overall quality of life, it has its own set of physical, psychological, and social issues along with complications. ${ }^{79}$ Complications vary with the type of ostomy and can be classified based on the time of onset.

\section{Very early complications (days after the procedure)}

It is often related to technical issues with the procedure, requiring correction. ${ }^{80}$

\section{Early complications (within 3 months of the procedure)}

It is often related to suboptimal site selection for ostomy, or patient-related factors, such as age, obesity (higher body mass index), poor nutritional status, diabetes mellitus, higher American Society of Anesthesiologists class, smoking, procedure setting (emergency vs. elective), and underlying malignancy. ${ }^{81,82}$ Early complications include stomal bleeding, ischemia, necrosis or retraction, or mucocutaneous separation.

\section{Late complications (more than 3 months after the procedure)}

A temporary ostomy is usually reversed in 3 months; hence, late complications are described only for a permanent procedure. ${ }^{83}$ Risk factors implicated in the development of late complications include inadequate mobilization of the bowel with a resultant height of stoma $<10 \mathrm{~mm}$, inappropriate size of the aperture, duration of the stoma, increased intra-abdominal pressure secondary to conditions like obesity or chronic obstructive pulmonary disease, and emergency surgery. ${ }^{82,84,85}$ The most frequently encountered late complications include parastomal hernia, stomal prolapse, and stomal stenosis. ${ }^{81}$

\section{Skin complications (any time after the procedure)}

They are frequently encountered with an ostomy and are caused due to the breakdown of the skin around the ostomy site. ${ }^{81}$ The severity can vary from minor skin trauma, dermatitis, ulceration, and pyoderma gangrenosum, which is commonly seen in patients with Crohn's disease. ${ }^{81}$

\section{PROGNOSIS OF RADIATION PROCTITIS}

The prognosis of RP depends on the type and severity of the radiation-induced injury. In the literature, a significant decrease in the health-related quality of life in up to $30 \%$ of patients with severe disease have been reported. ${ }^{86}$ On the other hand, acute RP is often self-limiting with minimal complications. It is also worth noting that patients with RP are at risk of developing secondary malignancies, the majority of which are colon and rectal cancers. ${ }^{87}$

\section{CONCLUSIONS}

$\mathrm{RP}$, also referred to as radiation proctopathy, is characterized by damage to the rectal epithelium secondary to ionizing radiation therapy. Based on the initiation of symptoms after RT, it can be classified as acute or chronic RP. Patients with acute RP may present with diarrhea, nausea, cramps, tenesmus, urgency, mucus discharge, and minor bleeding. Chronic RP 
patients may have all the symptoms of acute RP; however, they tend to be severe, with additional manifestations such as malabsorption, severe bleeding, strictures, perforations, fistulas, fecal incontinence, and bowel obstruction. The diagnosis of $\mathrm{RP}$ can be established via direct visualization through rigid or flexible sigmoidoscopy. Acute RP is often self-limiting, and approximately $20 \%$ of the patients may require interruption of therapy. However, patients with chronic RP may require extensive therapy based on their grades. Complications of chronic RP include bowel perforation, colitis, severe bleeding, fistula formation, and malignancy secondary to radiation. The overall prognosis of RP depends on the type and severity of the radiation-induced injury.

\section{Conflicts of Interest}

The authors have no potential conflicts of interest.

Funding

None.

Author Contributions

Conceptualization: Dushyant Singh Dahiya, Asim, Kichloo, Faiz Tuma, Michael Stanley Albosta, Farah Wani

Data curation: DSD, AK, FT, MSA, FW

Methodology: DSD, AK, FT, MSA, FW

Writing-original draft: DSD, AK, FT, MSA, FW

Writing-review\&editing: DSD, AK, FT, MSA, FW

\section{ORCID}

Dushyant Singh Dahiya Asim, Kichloo

Faiz Tuma

Michael Stanley Albosta

Farah Wani https://orcid.org/0000-0002-8544-9039 https://orcid.org/0000-0003-4788-8572 https://orcid.org/0000-0001-9065-8727 https://orcid.org/0000-0003-4187-4911 https://orcid.org/0000-0002-4683-6845

\section{REFERENCES}

1. Gianfaldoni S, Gianfaldoni R, Wollina U, Lotti J, Tchernev G, Lotti T. An overview on radiotherapy: from its history to its current applications in dermatology. Open Access Maced J Med Sci 2017;5:521-525.

2. Röntgen WC. Eine neue Art von Strahlen. Vorläufige Mitteilung. Vol. 30. Würzburg: Sitzungsberichte der Physikalisch-medizinischen Gesellschaft zu Würzburg; 1895. p. 132-141.

3. Grubbé EH. Priority in the therapeutic use of X-rays. Radiology 1933;21:156-162.

4. Becquerel $\mathrm{H}$, Curie P. Action physiologiques des rayons du radium. C R Acad Sci Gen 1901;132:1289-1291.

5. Tward JD, Anker CJ, Gaffney DK, Bowen GM. Radiation therapy and skin cancer. Modern practices in radiation therapy. Rijeka: InTech; 2012. p. 207-246.

6. Chen HHW, Kuo MT. Improving radiotherapy in cancer treatment: promises and challenges. Oncotarget 2017;8:62742-62758.

7. Siegel RL, Miller KD, Jemal A. Cancer statistics, 2019. CA Cancer J Clin 2019;69:7-34.

8. Miller KD, Nogueira L, Mariotto AB, et al. Cancer treatment and survivorship statistics, 2019. CA Cancer J Clin 2019;69:363-385.
9. Bryant AK, Banegas MP, Martinez ME, Mell LK, Murphy JD. Trends in radiation therapy among cancer survivors in the United States, 20002030. Cancer Epidemiol Biomarkers Prev 2017;26:963-970.

10. Baumann M, Krause M, Overgaard J, et al. Radiation oncology in the era of precision medicine. Nat Rev Cancer 2016;16:234-249.

11. Do NL, Nagle D, Poylin VY. Radiation proctitis: current strategies in management. Gastroenterol Res Pract 2011;2011:917941.

12. Terasawa T, Dvorak T, Ip S, Raman G, Lau J, Trikalinos TA. Systematic review: charged-particle radiation therapy for cancer. Ann Intern Med 2009;151:556-565.

13. Melian E, Mageras GS, Fuks Z, et al. Variation in prostate position quantitation and implications for three-dimensional conformal treatment planning. Int J Radiat Oncol Biol Phys 1997;38:73-81.

14. Fraass BA, Kessler ML, McShan DL, et al. Optimization and clinical use of multisegment intensity-modulated radiation therapy for high-dose conformal therapy. Semin Radiat Oncol 1999;9:60-77.

15. Shah SA, Cima RR, Benoit E, Breen EL, Bleday R. Rectal complications after prostate brachytherapy. Dis Colon Rectum 2004;47:1487-1492.

16. Lesperance RN, Kjorstadt RJ, Halligan JB, Steele SR. Colorectal complications of external beam radiation versus brachytherapy for prostate cancer. Am J Surg 2008;195:616-620; discussion 620.

17. Kennedy GD, Heise CP. Radiation colitis and proctitis. Clin Colon Rectal Surg 2007;20:64-72.

18. McKeown DG, Goldstein S. Radiation proctitis. In: StatPearls. Treasure Island (FL): StatPearls Publishing; 2020.

19. Denton A, Forbes A, Andreyev J, Maher EJ. Non surgical interventions for late radiation proctitis in patients who have received radical radiotherapy to the pelvis. Cochrane Database Syst Rev 2002;CD003455.

20. Grodsky MB, Sidani SM. Radiation proctopathy. Clin Colon Rectal Surg 2015;28:103-111.

21. Tagkalidis PP, Tjandra JJ. Chronic radiation proctitis. ANZ J Surg 2001;71:230-237.

22. Gilinsky NH, Burns DG, Barbezat GO, Levin W, Myers HS, Marks IN. The natural history of radiation-induced proctosigmoiditis: an analysis of 88 patients. Q J Med 1983;52:40-53.

23. Lucarotti ME, Mountford RA, Bartolo DC. Surgical management of intestinal radiation injury. Dis Colon Rectum 1991;34:865-869.

24. Zeitlin SI, Sherman J, Raboy A, Lederman G, Albert P. High dose combination radiotherapy for the treatment of localized prostate cancer. J Urol 1998;160:91-95; discussion 95-96.

25. Buchi K. Radiation proctitis: therapy and prognosis. JAMA 1991;265: 1180.

26. Wang CJ, Leung SW, Chen HC, et al. The correlation of acute toxicity and late rectal injury in radiotherapy for cervical carcinoma: evidence suggestive of consequential late effect (CQLE). Int J Radiat Oncol Biol Phys 1998;40:85-91.

27. Willett CG, Ooi CJ, Zietman AL, et al. Acute and late toxicity of patients with inflammatory bowel disease undergoing irradiation for abdominal and pelvic neoplasms. Int J Radiat Oncol Biol Phys 2000;46:995-998.

28. Hoffman R, Welton ML, Klencke B, Weinberg V, Krieg R. The significance of pretreatment $\mathrm{CD} 4$ count on the outcome and treatment tolerance of HIV-positive patients with anal cancer. Int J Radiat Oncol Biol Phys 1999;44:127-131.

29. Housri N, Yarchoan R, Kaushal A. Radiotherapy for patients with the human immunodeficiency virus: are special precautions necessary? Cancer 2010;116:273-283.

30. Newhauser WD, Berrington de Gonzalez A, Schulte R, Lee C. A review of radiotherapy-induced late effects research after advanced technology treatments. Front Oncol 2016;6:13.

31. Beard CJ, Propert KJ, Rieker PP, et al. Complications after treatment with external-beam irradiation in early-stage prostate cancer patients: a prospective multiinstitutional outcomes study. J Clin Oncol 1997;15:223229.

32. Coia LR, Myerson RJ, Tepper JE. Late effects of radiation therapy on the 
gastrointestinal tract. Int J Radiat Oncol Biol Phys 1995;31:1213-1236.

33. Gérard J-P, Conroy T, Bonnetain F, et al. Preoperative radiotherapy with or without concurrent fluorouracil and leucovorin in T3-4 rectal cancers: results of FFCD 9203. J Clin Oncol 2006;24:4620-4625.

34. Bosset JF, Collette L, Calais G, et al. Chemotherapy with preoperative radiotherapy in rectal cancer. N Engl J Med 2006;355:1114-1123.

35. Yang TJ, Oh JH, Son $\mathrm{CH}$, et al. Predictors of acute gastrointestinal toxicity during pelvic chemoradiotherapy in patients with rectal cancer. Gastrointest Cancer Res 2013;6:129-136.

36. Lin A, Abu-Isa E, Griffith KA, Ben-Josef E. Toxicity of radiotherapy in patients with collagen vascular disease. Cancer 2008;113:648-653.

37. Chon BH, Loeffler JS. The effect of nonmalignant systemic disease on tolerance to radiation therapy. Oncologist 2002;7:136-143.

38. Morris KA, Haboubi NY. Pelvic radiation therapy: between delight and disaster. World J Gastrointest Surg 2015;7:279-288.

39. Haboubi N. Pathology and pathogenesis of radiation bowel disease: histopathological appraisal in the clinical setting. EMJ Gastroenterol 2018;7:113-119.

40. Haboubi NY, El-Zammar O, O’Dwyer ST, James RJ. Radiation bowel disease: pathogenesis and management. Colorectal Dis 2000;2:322-329.

41. Metheetrairut C, Slack FJ. MicroRNAs in the ionizing radiation response and in radiotherapy. Curr Opin Genet Dev 2013;23:12-19.

42. Williams JM, Duckworth CA, Burkitt MD, Watson AJM, Campbell BJ, Pritchard DM. Epithelial cell shedding and barrier function: a matter of life and death at the small intestinal villus tip. Vet Pathol 2015;52:445455.

43. Okunieff $\mathrm{P}$, Cornelison T, Mester M, et al. Mechanism and modification of gastrointestinal soft tissue response to radiation: role of growth factors. Int J Radiat Oncol Biol Phys 2005;62:273-278.

44. Shadad AK, Sullivan FJ, Martin JD, Egan LJ. Gastrointestinal radiation injury: symptoms, risk factors and mechanisms. World J Gastroenterol 2013;19:185-198.

45. Rieder F, Brenmoehl J, Leeb S, Schölmerich J, Rogler G. Wound healing and fibrosis in intestinal disease. Gut 2007;56:130-139.

46. Villasanta U. Complications of radiotherapy for carcinoma of the uterine cervix. Am J Obstet Gynecol 1972;114:717-726.

47. François S, Bensidhoum M, Mouiseddine M, et al. Local irradiation not only induces homing of human mesenchymal stem cells at exposed sites but promotes their widespread engraftment to multiple organs: a study of their quantitative distribution after irradiation damage. Stem Cells 2006;24:1020-1029.

48. François S, Mouiseddine M, Mathieu N, et al. Human mesenchymal stem cells favour healing of the cutaneous radiation syndrome in a xenogenic transplant model. Ann Hematol 2007;86:1-8.

49. Paris F, Fuks Z, Kang A, et al. Endothelial apoptosis as the primary lesion initiating intestinal radiation damage in mice. Science 2001;293:293-297.

50. Bentzen SM. Preventing or reducing late side effects of radiation therapy: radiobiology meets molecular pathology. Nat Rev Cancer 2006;6:702-713.

51. Cotti G, Seid V, Araujo S, Souza AHS e, Kiss D rio R, Habr-Gama A. Conservative therapies for hemorrhagic radiation proctitis: a review. Rev Hosp Clin Fac Med Sao Paulo 2003;58:284-292.

52. Vanneste BGL, Van De Voorde L, de Ridder RJ, Van Limbergen EJ, Lambin P, van Lin EN. Chronic radiation proctitis: tricks to prevent and treat. Int J Colorectal Dis 2015;30:1293-1303.

53. Cox JD, Stetz J, Pajak TF. Toxicity criteria of the Radiation Therapy Oncology Group (RTOG) and the European Organization for Research and Treatment of Cancer (EORTC). Int J Radiat Oncol Biol Phys 1995;31:1341-1346.

54. Lund J-Å, Kaasa S, Wibe A, Widmark A, Fransson P. Late radiation effects to the rectum and anus after treatment for prostate cancer; validity of the LENT/SOMA score. Acta Oncol 2013;52:727-735.

55. Cancer Therapy Evaluation Program. Common Terminology Criteria for Adverse Events (CTCAE) Version 5.0 [Internet]. Bethesda (MD):
CTEP; c2017 [updated 2017 Nov 27; cited 2021 Apr 15]. Available from: https://ctep.cancer.gov/protocolDevelopment/electronic_applications/ docs/CTCAE_v5_Quick_Reference_5x7.pdf.

56. Porouhan P, Farshchian N, Dayani M. Management of radiation-induced proctitis. J Family Med Prim Care 2019;8:2173-2178.

57. Katsanos KH, Sigounas DE, Christodoulou DK, Tsianos EV. Grading acute radiation bowel injury an unaddressed issue. Ann Gastroenterol 2012;25:65

58. Zhong Q-H, Liu Z-Z, Yuan Z-X, et al. Efficacy and complications of argon plasma coagulation for hemorrhagic chronic radiation proctitis. World J Gastroenterol 2019;25:1618-1627.

59. Ali F, Hu KY. Evaluation and management of chronic radiation proctitis. Dis Colon Rectum 2020;63:285-287.

60. Tabaja L, Sidani SM. Management of radiation proctitis. Dig Dis Sci 2018;63:2180-2188.

61. Hanson B, MacDonald R, Shaukat A. Endoscopic and medical therapy for chronic radiation proctopathy: a systematic review. Dis Colon Rectum 2012;55:1081-1095.

62. Paquette IM, Vogel JD, Abbas MA, Feingold DL, Steele SR, Clinical practice guidelines Committee of The American Society of Colon and Rectal Surgeons. The American Society of Colon and Rectal Surgeons clinical practice guidelines for the treatment of chronic radiation proctitis. Dis Colon Rectum 2018;61:1135-1140.

63. Hille A, Herrmann MKA, Kertesz T, et al. Sodium butyrate enemas in the treatment of acute radiation-induced proctitis in patients with prostate cancer and the impact on late proctitis. A prospective evaluation. Strahlenther Onkol 2008;184:686-692.

64. Isenberg GA, Goldstein SD, Resnik AM. Formalin therapy for radiation proctitis. JAMA 1994;272:1822.

65. Dziki Ł, Kujawski R, Mik M, Berut M, Dziki A, Trzciński R. Formalin therapy for hemorrhagic radiation proctitis. Pharmacol Rep 2015;67:896-900.

66. al-Sabbagh R, Sinicrope FA, Sellin JH, Shen Y, Roubein L. Evaluation of short-chain fatty acid enemas: treatment of radiation proctitis. Am J Gastroenterol 1996;91:1814-1816.

67. Swan MP, Moore GTC, Sievert W, Devonshire DA. Efficacy and safety of single-session argon plasma coagulation in the management of chronic radiation proctitis. Gastrointest Endosc 2010;72:150-154.

68. Ravizza D, Fiori G, Trovato C, Crosta C. Frequency and outcomes of rectal ulcers during argon plasma coagulation for chronic radiation-induced proctopathy. Gastrointest Endosc 2003;57:519-525.

69. Ben Soussan E, Mathieu N, Roque I, Antonietti M. Bowel explosion with colonic perforation during argon plasma coagulation for hemorrhagic radiation-induced proctitis. Gastrointest Endosc 2003;57:412413.

70. Barbatzas C, Spencer GM, Thorpe SM, Sargeant LR, Bown SG, Carbatzas C. Nd:YAG laser treatment for bleeding from radiation proctitis. Endoscopy 1996;28:497-500.

71. Lee JK, Agrawal D, Thosani N, et al. ASGE guideline on the role of endoscopy for bleeding from chronic radiation proctopathy. Gastrointest Endosc 2019;90:171-182.e1.

72. Clarke RE, Tenorio LMC, Hussey JR, et al. Hyperbaric oxygen treatment of chronic refractory radiation proctitis: a randomized and controlled double-blind crossover trial with long-term follow-up. Int J Radiat Oncol Biol Phys 2008;72:134-143.

73. Dall'Era MA, Hampson NB, Hsi RA, Madsen B, Corman JM. Hyperbaric oxygen therapy for radiation induced proctopathy in men treated for prostate cancer. J Urol 2006;176:87-90.

74. Jao SW, Beart RW, Gunderson LL. Surgical treatment of radiation injuries of the colon and rectum. Am J Surg 1986;151:272-277.

75. McCrone LF, Neary PM, Larkin J, McCormick P, Mehigan B. The surgical management of radiation proctopathy. Int J Colorectal Dis 2017;32:1099-1108

76. Anseline PF, Lavery IC, Fazio VW, Jagelman DG, Weakley FL. Radia- 
tion injury of the rectum: evaluation of surgical treatment. Ann Surg 1981;194:716-724.

77. Pricolo VE, Shellito PC. Surgery for radiation injury to the large intestine. Variables influencing outcome. Dis Colon Rectum 1994;37:675684.

78. Yuan Z-X, Ma T-H, Wang H-M, et al. Colostomy is a simple and effective procedure for severe chronic radiation proctitis. World J Gastroenterol 2016;22:5598-5608.

79. Nichols TR. Quality of life in US residents with ostomies assessed via the SF36v2: role-physical, bodily pain, and general health domain. J Wound Ostomy Continence Nurs 2016;43:280-287.

80. Persson E, Berndtsson I, Carlsson E, Hallén A-M, Lindholm E. Stoma-related complications and stoma size - a 2-year follow up. Colorectal Dis 2010;12:971-976.

81. Shabbir J, Britton DC. Stoma complications: a literature overview. Colorectal Dis 2010;12:958-964.

82. Arumugam PJ, Bevan L, Macdonald L, et al. A prospective audit of sto- mas--analysis of risk factors and complications and their management. Colorectal Dis 2003;5:49-52.

83. Shellito PC. Complications of abdominal stoma surgery. Dis Colon Rectum 1998;41:1562-1572.

84. Harris DA, Egbeare D, Jones S, Benjamin H, Woodward A, Foster ME. Complications and mortality following stoma formation. Ann R Coll Surg Engl 2005;87:427-431.

85. Suwanabol PA, Hardiman KM. Prevention and management of colostomy complications: retraction and stenosis. Dis Colon Rectum 2018;61:1344-1347.

86. Lev EL, Eller LS, Gejerman G, et al. Quality of life of men treated with brachytherapies for prostate cancer. Health Qual Life Outcomes 2004;2:28.

87. Liauw SL, Sylvester JE, Morris CG, Blasko JC, Grimm PD. Second malignancies after prostate brachytherapy: incidence of bladder and colorectal cancers in patients with 15 years of potential follow-up. Int J Radiat Oncol Biol Phys 2006;66:669-673. 